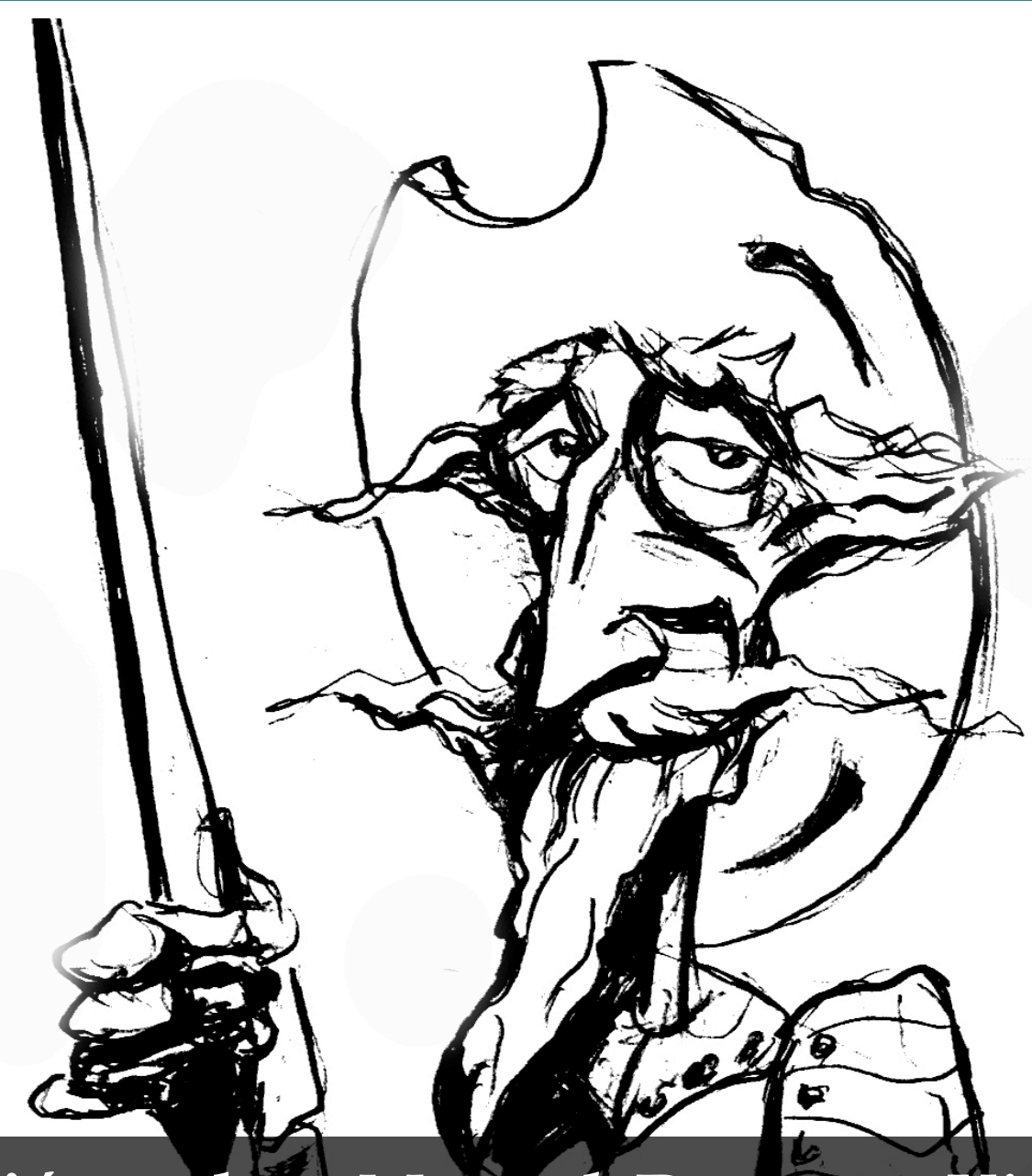

Discusión sobre Manuel Dorrego. Vida y muerte de un líder popular, de Gabriel DiMeglio.

[Julio Pinto Vallejos, Daniel Santilli, Gabriel Di Meglio] 


\section{Comentario a DI MEGLIO, Gabriel Manuel Dorrego. Vida y muerte de un líder popular, EDHASA, Buenos Aires, 2014, 424 páginas.}

\section{A comment to DI MEGLIO, Gabriel Manuel Dorrego. Vida y muerte de un líder popular, EDHASA, Buenos Aires, 2014, 424 pages.}

Julio Pinto VALlejos

\section{Resumen}

El texto que se presenta a continuación comenta el libro de Gabriel Di Meglio, Manuel Dorrego. Vida y muerte de un líder popular, una biografía dedicada a una de las figuras más emblemáticas del proceso independentista rioplatense, indiscutido líder popular y fundador del federalismo. Se articula en torno a tres divagaciones (historiográficas), dos provocaciones (interpretativas), $\mathrm{y}$ un doble enigma (literario y musical).

Palabras clave: Dorrego - Independencia rioplatense - biografía histórica - Buenos Aires federalismo

\begin{abstract}
This article reviews the recent book by Gabriel Di Meglio, Manuel Dorrego. Vida y muerte de un líder popular, a biography of one of the most symbolic figures of the independence wars in the River Plate, unquestioned popular leader and founding father of that region's federal party. It is built around three (historiographic) digressions, two (interpretative) taunts, and a double (literary and musical) enigma.
\end{abstract}

Keywords: Dorrego - Independence in the River Plate - historical biography - Buenos Aires federalism

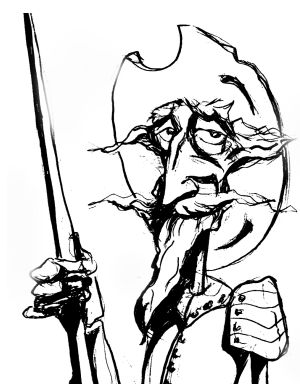

Recibido con pedido de publicación el 5 de octubre de 2016

Aceptado para su publicación el 30 de octubre de 2016

Versión definitiva recibida el 15 de noviembre de 2016

Julio Pinto Vallejos, Universidad de Santiago de Chile (USACH), Chile; e-mail: julio.pinto@usach.cl

Esta obra se publica bajo licencia Creative Commons. Atribución-NoComercialCompartirIgual 4.0 Internacional

Pinto Vallejos, Julio "Comentario a DI MEGLIO, Gabriel Manuel Dorrego. Vida y muerte de un líder popular", Prohistoria, Año XIX, núm. 26, dic. 2016, pp. 127-131. 
No resulta fácil abordar en clave crítica una obra tan bien lograda y tan bien terminada en casi todos sus aspectos: sólidamente documentada, ágil y convincentemente estructurada, y muy bien escrita. Ante esa dificultad, he optado por articular mi comentario en torno a tres divagaciones, dos provocaciones, y un enigma. Paso a exponerlas a continuación:

\section{Tres Divagaciones (Historiográficas)}

El libro que se comenta forma parte de un fenómeno generalizado de recuperación de la biografía como género historiográfico legítimo y apreciado. Estigmatizada durante décadas como una de las expresiones más descollantes de un abordaje "positivista", obsesionado con los grandes personajes y los acontecimientos vistosos, abordaje severamente descalificado por las vertientes "estructuralistas" que hegemonizaron la disciplina durante gran parte del siglo XX (marxistas, seguidores de Annales, cliómetras y cuantitativistas), la biografía ha retornado triunfalmente de la mano de un "revisionismo" post-giro cultural que vuelve a poner el énfasis en lo particular, en la "agencia" de los sujetos, y en la contingencia del quehacer histórico. Es verdad que la vida de una persona también puede trabajarse en un registro más "estructural", atento al peso de las fuerzas más impersonales de la historia y a la sedimentación de la acción colectiva en la larga duración. Hasta cierto punto, ese es el sello que distingue a otra de las biografías comentadas en este encuentro (la de Juan Manuel de Rosas elaborada por Raúl Fradkin y Jorge Gelman), en la que actor y estructura interactúan de manera permanente y estrecha, y en la que, a la postre, el actor emerge como una suerte de encarnación de estructuras ajenas a su control y voluntad. El Dorrego de Di Meglio no comparte ese énfasis, sino que por el contrario, carga decididamente las tintas hacia la excepcionalidad, el voluntarismo y la irrefrenable expresividad del personaje. En ese sentido, es una obra reconociblemente, por emplear un concepto provocador, "postestructuralista".

Y sin embargo, si bien la biografía se presta admirablemente para resaltar precisamente lo indeterminado y lo no previsible del accionar humano, hay otro de sus rasgos que apunta más bien en sentido contrario. Porque la vida de una persona, con su trayectoria claramente articulada entre un comienzo y un fin, y con la facilidad con que sus etapas sucesivas pueden hilvanarse en una narrativa más o menos coherente, hasta teleológica, también se presta para resaltar la inteligibilidad del quehacer humano, y el deber del historiador o la historiadora de discernir y recuperar dicha inteligibilidad. Se incurre así en un gesto "humanista" o "racionalista" que no dialoga muy fluidamente con las preferencias post-estructurales, por lo general recelosas de la lucidez de los sujetos, de la supuesta coherencia de sus actos, y hasta de la noción misma, necesariamente unitaria e integrada, de sujeto. Vista desde ese ángulo, la obra de Di Meglio podría antojarse más bien "conservadora", en el sentido que 
otorga a dicho término la crítica postmoderna respecto de sus predecesores "cientificistas".

Pero Di Meglio vuelve a situarse derechamente en el campo de lo "renovado" cuando arranca la vida de su personaje de los moldes porfiadamente nacionalistas en que la historiografía tradicional ha enmarcado las biografías de los próceres independentistas, habitual y casi obligadamente asociadas a los estados nacionales que, mirados en retrospectiva, ayudaron a fundar. Lejos de esa mirada, Di Meglio se ha cuidado más bien de subrayar la trayectoria profundamente "transnacional" de Dorrego, cuya acción se desplegó en un abanico territorial que abarca lo que hoy en día son la Argentina, Chile, Bolivia, Uruguay, el Caribe y Estados Unidos. Para lograr este efecto ha emprendido una verdadera odisea bibliográfica y documental, reuniendo datos y testimonios que permiten llenar prácticamente todas las lagunas de esa peripatética y ubicua trayectoria (y de paso reforzando lo que es uno de los puntos fuertes de esta biografía: su voluminosa base empírica). Rompe así con el sesgo nacionalista de este tipo de obras, y se inscribe en el "giro transnacional" que ha irrumpido como una de las últimas innovaciones en nuestro quehacer disciplinario.

De esta forma, y para cerrar estas "divagaciones historiográficas", concluyo diciendo que es difícil encasillar la biografía de Dorrego en algún campo teórico o generacional determinado, oscilando entre enfoques "accionalistas" o "estructuralistas", modernos o postmodernos, según cuál sea el ángulo desde el que se la mire. Lejos de ser una debilidad, este "eclecticismo" confiere al libro una riqueza, una complejidad y una flexibilidad propias del mejor trabajo historiográfico, porque es lo que más se acerca al carácter mismo de la vida en sociedad.

\section{Dos Provocaciones (Interpretativas)}

Desplazándonos desde el marco historiográfico hacia las hipótesis ofrecidas por Di Meglio para dar cuenta del sentido y trascendencia de la vida de su biografiado, hay dos que me parecen levemente problemáticas, y sobre las que me atrevo a llamar la atención.

La primera apunta hacia la fuerza o la convicción que, según Di Meglio, motivó no solo el accionar de Dorrego, sino de casi todos los actores que ocupan las páginas de su libro: el patriotismo, definido en clave americanista y anti-española. Según nos asegura en la página 54, “la noción de patria -un concepto que remitía al territorio en que se vivía en clave comunitaria y sentimental- devino el principio identitario fundamental (el énfasis es mío) a partir de 1810: había que servirla, salvarla, liberarla". Y luego, nuevamente en las páginas 129-130: “Esta noción era la más fuerte a la que se podía apelar en la 
época, ya que el patriotismo era el principio de identidad colectiva más importante después de la Revolución".

Es verdad que Di Meglio se cuida, al menos en la primera de las citas reproducidas, de advertir que la noción de patria también formaba parte "de los tres pilares simbólicos de la sociedad hispana junto con Dios y el rey", y que por tanto también los "fidelistas", como él denomina (acertadamente, a mi juicio) a los realistas al menos hasta 1814, podían reivindicarla en beneficio de su propia causa. Pero al convertirla en un factor identitario común y además anterior a 1810, se hace problemática su identificación como el "principio identitario fundamental" posterior a esa fecha. De ser efectivamente un fenómeno posterior, la pregunta que surge es cómo adquirió esa condición con tanta rapidez y con tanta fuerza. De no serlo, la pregunta es qué lo diferenciaba del patriotismo colonial, y por qué este no resultó a la postre más poderoso que el "revolucionario". No es, por cierto, una incógnita sencilla de resolver, pero la obra la deja abierta y perturbadoramente planteada.

Mi segunda provocación apunta a una tesis posiblemente más central para el sentido profundo del libro (hasta el punto de ser incluso parte de su título), y es la que refiere al carácter "popular" del liderazgo de Dorrego. Es verdad que Di Meglio documenta más allá de cualquier duda que su personaje efectivamente supo concitar y conservar adhesiones populares poderosísimas, y que sus contemporáneos lo identificaron repetidamente como un verdadero "tribuno de la plebe". Pero más allá de la existencia misma de este sentimiento, lo que me intriga es el carácter y los fundamentos de dicha "popularidad". ¿Se trataba simplemente de una cuestión "empática", de un particular don de Dorrego para dialogar a contrapelo de las rígidas jerarquías sociales de su época? ¿Se trataba de un mecanismo más bien instrumental o "clientelar", orientado a obtener apoyos militares y políticos a cambio de reciprocidades más bien simbólicas? ¿O subyacía a esas adhesiones un trasfondo más "programático", en el sentido de inclinarse por una visión más igualitaria o más justa de las relaciones sociales?

La información concreta entregada en el libro no aporta elementos para sustentar esta última lectura. Más bien al contrario: su paso por Haití indujo en Dorrego reflexiones muy poco "igualitarias", y no precisamente empáticas respecto del fin de la esclavitud, al menos en las condiciones en que ello ocurrió en dicha isla. En otras partes del texto se reconoce que la figura de Dorrego "puede ser recuperada desde una perspectiva liberal" (p. 384), o que su "populismo" era tributario de un republicanismo de corte "jeffersoniano", más celebratorio de la libertad individual que de la igualdad o la justicia social (pp. 151-152). No se trata por cierto de exigirle a Dorrego posturas igualitaristas que habrían resultado bastante anacrónicas para su época y para la sociedad en la que se formó y desenvolvió (lo que no significa que no hayan existido). Pero como la historiografía se mueve simultáneamente entre el pasado y el presente, 
destacar el carácter "popular" de su liderazgo, como se hace en esta biografía, sin hacerse cargo expresamente de los matices y las ambivalencias que dicho adjetivo suscita en un lector actual, puede generar expectativas o preguntas que en sus páginas quedan hasta cierto punto sin abordar, al menos no directamente.

\section{Y por último, un (doble) enigma (literario y musical)}

Gabriel Di Meglio ha optado por encabezar cada uno de los capítulos de su biografía con epígrafes extraídos de canciones rockeras. ¿Dónde reside ese misterioso vínculo entre Manuel Dorrego y el rock, que indujo a nuestro autor a ir marcando los hitos de su vida con "señales" extraídas de esa tradición musical, y que para él resulta tan evidente que ni siquiera vale la pena explicárselo al lector? ¿O estamos simplemente frente a un émulo de Umberto Eco en El nombre de la rosa...?

Santiago de Chile, 30 de agosto de 2016 


\section{Comentario a Di Meglio, Gabriel Manuel Dorrego. Vida y muerte de un líder popular, Edhasa, Buenos Aires, 2014, 416 pág. ISBN 978- 987-628-297-0}

\section{Comment to Di Meglio, Gabriel Manuel Dorrego. Vida y muerte de un líder popular, Edhasa, Buenos Aires, 2014, 416 pág. ISBN 978-987-628-297-0}

DANIEL SANTILLI

\section{Resumen}

El presente trabajo analiza el capítulo 8 del texto de Gabriel Di Meglio y se extiende en consideraciones acerca de otras partes del mismo libro. Se plantean preguntas al autor y se discute con él acerca de algunas aseveraciones. Al final se recogen respuestas de Gabriel Di Meglio.

Palabras clave: Manuel Dorrego - feliz experiencia - federalismo - sectores populares

\begin{abstract}
In this paper we analyse chapter 8 of Gabriel Di Meglio's book and advance some comments on others parts of the tome. We debate with him some of his claims and asked him a few questions. His answers are included in the final section.
\end{abstract}

Keywords: Manuel Dorrego - feliz experiencia - federalism - popular classes

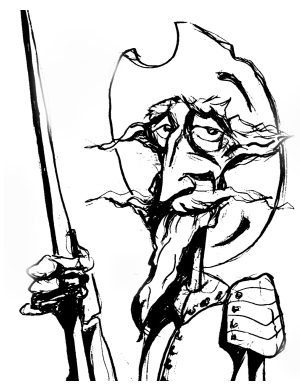

Recibido con pedido de publicación el 5 de octubre de 2016 Aceptado para su publicación el 30 de octubre de 2016 Versión definitiva recibida el 15 de noviembre de 2016

Daniel Santilli, Universidad de Buenos Aires, Instituto Ravignani, Argentina; e-mail: dvsantilli@gmail.com

Esta obra se publica bajo licencia Creative Commons. Atribución-NoComercial- (cc) EY-NC-SA CompartirIgual 4.0 Internacional

Santilli, Daniel "Comentario a Di Meglio, Gabriel. Manuel Dorrego. Vida y muerte de un líder popular", Prohistoria, Año XIX, núm. 26, dic. 2016, pp. 133-138. 
Me ha sido encargado leer y comentar el capítulo 8 del libro de Gabriel Di Meglio Manuel Dorrego. Vida y muerte de un líder popular. Trataré de ceñirme a ese fragmento, pero en algunos momentos abandonaré ese brete.

Gabriel Di Meglio se revela en este libro como un creador de climas. Intenta otorgarle, y lo logra, importancia, dentro del relato histórico, a aquello que proponía la microhistoria acerca de la relevancia de la narración, más allá de la investigación en concreto. $\mathrm{Y}$ es pertinente porque, dado el género elegido para el texto, la biografía se presta para ello, para la narración cronológica de aspectos de la vida del Coronel Dorrego, sin olvidar para nada el contexto en la cual se desarrolló.

El libro comienza con el relato del funeral de Dorrego en Buenos Aires, luego de restaurada la legalidad en diciembre de 1829. Más allá de la veracidad del relato, según los testigos que cita, el modo de presentar la narración es atrapante, como para que impulse al lector, después de leer ese párrafo inicial, a continuar leyendo el libro por cierto. Y esa puesta en escena se repite en el capítulo 10, el martirio.

Pero va la puesta en escena. Me permito leer el último párrafo cargado de dramatismo.

"Apenas puedo reconstruir lo que sigue. Lo sientan en el banquillo, junto a un corral. Le vendan los ojos con un pañuelo. Ninguno de los jefes se hace presente. Lavalle tampoco, espera en su habitación. Los soldados apuntan, una voz da la orden. Ya las descargas, las balas que le rompen el pecho. Manuel Dorrego ha muerto." (p. 351)

Es imposible no conmoverse. La oración inicial del párrafo, más allá de hacer referencia a la dificultad material del historiador de reconstruir verídicamente lo ocurrido, apela también a la imposibilidad de contarlo por la carga emocional del suceso.

Pero más allá de esta descripción, intento aquí hacer un análisis desde la ciencia histórica del texto, no de la técnica narrativa, que por cierto no deja de ser importante. $Y$, reitero, atrapante.

Di Meglio explica que la necesidad de una nueva biografía, agregada a las ya numerosas que existen sobre el personaje, se basa sobre todo en que cada generación escribe su propia versión de la historia, más motivada por la actualidad que por la estricta averiguación del pasado. O en todo caso, cada nueva investigación tiene que ver con el presente del investigador. Y las razones personales, siempre concurrentes en los historiadores cuando elegimos el objeto o el actor de nuestra investigación. Todo salpimentado con recuerdos familiares o personales, como nos tiene acostumbrado el autor desde su primer libro. 
El capítulo que me fue asignado es, junto con el 7, el del definitivo abandono de la carrera militar, la carrera abierta al talento, parafraseando a Hobsbawm, ${ }^{1}$ pero también a Tulio Halperín Donghi, ${ }^{2}$ que decía que esa era la trayectoria de todo miembro de la élite que pretendiese ascender en el Río de la Plata. En efecto, Dorrego, luego de su último exilio en la Banda Oriental, entiende que la paz promovida por Martín Rodríguez y Rosas puede incorporarlo como político, no ya como militar, porque su propuesta bélica no será efectiva ni viable. La élite quiere paz para los negocios.

En este capítulo, el 8, se demuestra que Manuel es mejor como político, e incluso como guerrero, que para los negocios. Y progresivamente será mejor político aún. La lectura de su viaje al norte parece demostrar eso. Si bien se supone que su desplazamiento es por negocios, la lectura que hace Di Meglio, basado en algunos testimonios, es que va a hacer política, "nacional" y continental. Va a entrevistarse y luego aliarse con Bustos e Ibarra. Significa que su apreciación de la política incluye ahora estos espacios, las provincias, antes minimizados desde su porteñismo. También el apoyo a los Treinta y tres orientales se puede leer desde la misma óptica. Por supuesto que desde otra mirada se puede observar como oportunismo, lo que no hace Di Meglio; el historiador juzga acciones, no es psicólogo. Ya sabemos, porque lo dice, que él simpatiza con el personaje, basado en su condición de líder de la plebe, en sus buenas relaciones con sus subalternos, con el pueblo raso. Sin embargo, muestra unos cuantos episodios desde los cuales es posible imaginar un cierto trato paternalista hacia la plebe. Reparte bienes y planazos.

Sus ambiciones "nacionales" pueden deducirse de su entrevista con Bolívar y de su deseo de conseguir una alianza para enfrentar al Imperio de Brasil, único espacio no republicano de Sud América. Bolívar, enemigo declarado del Antiguo Régimen, era un aliado predispuesto. Hay aquí una visión algo más profunda según Di Meglio, al intuir el inicio de la guerra. Me parece que no era la de Dorrego una lectura muy intrépida. Ya estaba en ciernes la guerra. Se había emprendido el camino sin retorno que llevaba al enfrentamiento con el Imperio.

La llegada al Congreso Constituyente como diputado por Santiago del Estero abre, a mi entender, la etapa más fecunda en lo político de su corta vida. Tal vez es el momento donde mejor se puede leer su pensamiento, sobre todo su accionar y su olfato político. Y porque parece que todo lo que proponen los unitarios encuentra su oposición. Por supuesto que fundada y muy bien

\footnotetext{
${ }^{1}$ HOBSBAWM, Eric La era de la revolución. 1789-1848, Crítica, Barcelona, 1997.

2 HALPERIN DONGHI, Tulio De la revolucion de independencia a la confederacion rosista, Vol. 3, Paidos, Buenos Aires, 1985. HALPERIN DONGHI, Tulio Revolución y Guerra. Formación de una élite dirigente en la Argentina criolla, Siglo XXI, Buenos Aires, 1972.
} 
fundada su opinión. Es un rasgo a pensar, si el oportunismo no forma parte del juego político, si aceptamos la corriente definición de la política como el arte de lo posible. En todo caso debe ser redefinido como olfato, sensibilidad, oído, todo aquello que quien quiera obtener apoyos en una sociedad como la que se estaba construyendo, basada en la legitimidad otorgada por la masa de los ciudadanos, debía poseer.

Su asunción del federalismo, mejor del confederacionismo, lo lleva a apoyar la destitución de un diputado santiagueño que desobedece a su gobernador. Está presente aquí el problema de la representación, tan caro a los estudios sobre historia política ¿los diputados son de la provincia o de la nación? Discusión abierta aún, con otros actores.

Pero no es fácil definir el federalismo y mantener la unidad del bloque federal, que además estaba en minoría. No hubo un proyecto de constitución federal para oponerle al proyecto unitario, estructurado y con mayoría. Di Meglio se pregunta, y coincidimos, ¿este es un déficit intelectual de Dorrego y de sus aliados? Por lo menos tres fracciones encuentra en el partido federal, antes popular; cuando se lo quiere llevar a nivel del conjunto de las provincias. Una primera, algunas provincias declaradas federales solo pretenden, que no es poco, compartir los ingresos aduaneros. Pero una fracción porteña, encabezada por los nuevos federales como Rosas y Anchorena, intentaba que cada provincia se mantenga con sus propios recursos, lo que significaba, como luego ocurrió, que Buenos Aires se apropiara de todos los recursos de su Aduana. Era el puerto de Buenos Aires la puerta de entrada y de salida prácticamente única de la futura Confederación.

Dorrego navega en ese mundo borrascoso interno, conformando la tercera facción del federalismo. Esto está muy cerca de la imagen que se forma Tulio Halperín Donghi, de su descolocación en el movimiento que él encarna.

El modelo de Dorrego y sus compañeros era el jeffersoniano, que limitaba al Estado central para mantener la soberanía de los estados y la igualdad, frenando el autoritarismo del poder central. Una especie de doble soberanía. Porque "La unidad tiende al absolutismo, a la monarquía" decía. Dejó entrever que incluía en el Estado federal a los indígenas como nación. No preveía su incorporación individual como ciudadanos, aquello que proclamó Castelli en el Alto Perú, y que buena parte de la élite liberal concedía entusiasmada. $\mathrm{O}$ sea, un nacionalismo basado en la restauración del virreinato, con los indígenas como otra nación.

Pero ese federalismo tenía un límite; rechazaba el de Artigas, Ramírez y Carreras, acérrimos enemigos de Buenos Aires y de él mismo, que tanto los combatió. Una muestra de su acendrado porteñismo. Sin embargo, no desmiente para nada que su inclinación hacia la plebe es similar en la forma a la del artiguismo. La diferencia está en que la plebe no estaba conformada igual. 
Su discurso se dirigía a los sectores subalternos urbanos y no a los "desposeídos rurales" orientales.

Su proyecto, como se ve, es político por sobre todo; no muestra Di Meglio que Dorrego tenga una posición tomada en la cuestión del sistema rentístico. Y digo rentístico y no económico, porque entiendo que nadie, todavía en ese tiempo, podía tener otra propuesta que la del librecambio. No creo que, como dice Nicolau, y cita Di Meglio, Dorrego estaba en el medio de dos facciones económicas que representaban intereses económicos diferentes.

Es decir, ya se vislumbra que toda la lucha facciosa tiene que ver con quién maneja los recursos de la aduana. ¿Sería una exageración decir que la historia del siglo XIX argentina, o de este lado del Río de la Plata, se podría reducir al manejo de los recursos de la Aduana? Visión demasiada simplificada que no me perdonarían los cultores de la historia política.

Sobre el pensamiento en ese tópico de Dorrego nada nos dice el autor y esa es mi pregunta. ¿nunca se expresó en ese sentido? Se podría pensar que, dado el federalismo que proponía, estaba más cerca de dejar librado a cada provincia a su propio recurso, tal como querían Rosas y los neofederales. Lo que lo haría mucho más porteño de lo que se entrevé en el capítulo que comento. De todos modos, porque no lo tenía, o porque no era conveniente darlo a conocer, no parece haber expresado su pensamiento en la materia. Esto, más allá de la pertenencia al grupo de labradores, según Di Meglio, porque era propietario de una chacra. Me permito dudar que sus intereses "de clase" pasen por tal pertenencia. Ya dijimos que su predicamento era más urbano que rural.

Su hora más memorable y su mayor acercamiento con la plebe se desarrolla durante el debate sobre la ciudadanía en el Congreso constituyente. Denuncia el retroceso de la facción unitaria, que cuando formaba parte del partido del orden promovió la ley de sufragio de 1821 y que ahora pretendía restringir el derecho a voto. Los argumentos de Dorrego son realmente impecables. Sin dudas, es el punto más alto de su discurso. Plantear que los dependientes pagan impuestos y consumen y no pueden influir en las elecciones es un argumento notable, de otro siglo, que además descoloca totalmente a sus contrincantes dejándolos parados en el espacio antipopular. Pero también encuentra su límite. Porque en definitiva él habla de igualdad de derechos, de oportunidades, limitadas en este caso a la ciudadanía.

Si lo trasladamos al plano económico social, el liberalismo debía asegurar la igualdad de oportunidades, la igualdad ante la ley (camino a recorrer, por cierto) pero nada decía de la de posición, parafraseando a François Dubet. $^{3}$ Su

\footnotetext{
${ }^{3}$ DUBET, François “Elegir para actuar", en Le monde diplomatique, 1 de marzo de 2016, pp. 12-13. DUBET, François Repensar la justicia social. Contra el mito de la igualdad de oportunidades, Siglo XXI Editores, Buenos Aires, 2011.
} 
lugar en la sociedad no le permitía proponer una igualación de las fortunas, es decir de posiciones. Si hubo algún proceso de disminución de la desigualdad o de mejora en el nivel de vida no fue un acto voluntario de la élite, ni de Dorrego.

\section{Una acotación fuera del capítulo mencionado}

José Carlos Chiaramonte, en una reseña para la revista $\tilde{\mathrm{N}}(14 / 01 / 15),{ }^{4}$ al poco tiempo de publicado el libro, se preguntaba por qué no movilizó sus apoyos populares para defenderse en 1829 , y se responde a sí mismo porque en realidad como miembro de la élite no podía traicionar a sus pares, su procedencia de clase no se lo permitió. Y deduce Chiaramonte que Dorrego no era un líder popular porque no había surgido de la misma plebe. Más allá de la discusión que puede generarse acerca del análisis de la procedencia de clase de un líder popular, este comportamiento es una constante entre los líderes populares. Le pasó a Rosas en 1852. Y tenemos casos más cercanos en nuestra historia, y la de América Latina. Me pregunto, y se lo traslado al autor, ¿ese era su límite? ¿No se animó a abrir la puerta a la plebe? ¿se trata de un límite de clase o de estrategia política? ¿no será que los lideres confían en sus fuerzas y su prestigio de manera tal que suponen que nadie se animará a enfrentarlos?

Es de recordar que este era un camino sin retorno, los que lo practicaron no volvieron, no consiguieron luego recomponer sus lazos con la élite. Le pasó a Artigas, le pasó a Rosas, a Güemes, para quedarnos solo en los contemporáneos.

Buenos Aires, julio de 2016

${ }^{4}$ CHIARAMONTE, José Carlos "Retrato de un líder federal y popular", en Revista N , 14 de enero de 2015. 


\title{
Respuesta a los comentarios de Julio Pinto Vallejos y Daniel Santilli sobre el libro de Gabriel Di Meglio, Manuel Dorrego. Vida y muerte de un líder popular, EDHASA, Buenos Aires, 2014.
}

\author{
Answer to comments of Julio Pinto and Daniel Santilli on Gabriel Di \\ Meglio's book, Manuel Dorrego. Vida y muerte de un líder popular, EDHASA, \\ Buenos Aires, 2014.
}

\section{GABRIEL Di MEGLIO}

\section{Resumen}

El presente es la respuesta a los comentarios de Julio Pinto Vallejos y Daniel Santilli sobre uno de los capítulos centrales del libro de Gabriel Di Meglio, la biografía de Manuel Dorrego.

Palabras clave: Dorrego - liderazgo popular - independencia de la región rioplatense biografía histórica

\begin{abstract}
This is the answer to the comments done by Julio Pinto Vallejos and Daniel Santilli, on one of the core chapters of Gabriel Di Meglio's book, a biography of Manuel Dorrego.
\end{abstract}

Keywords: Dorrego - popular leadership independence of the River Plate region historical biography

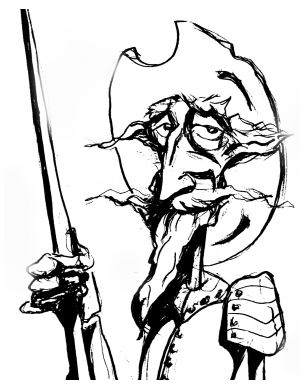

Recibido con pedido de publicación el 5 de octubre de 2016

Aceptado para su publicación el 30 de octubre de 2016

Versión definitiva recibida el 15 de noviembre de 2016

Gabriel Di Meglio, Universidad de Buenos Aires / Universidad Nacional de San Martín / Consejo Nacional de Investigaciones Científicas y Técnicas, Argentina; e-mail: gabrieldimeglio@gmail.com

Esta obra se publica bajo licencia Creative Commons. Atribución-NoComercial- (cc) EY-Nc-sa CompartirIgual 4.0 Internacional

Di Meglio, Gabriel "Respuesta a los comentarios de Julio Pinto Vallejos y Daniel Santilli sobre el libro de Gabriel Di Meglio, Manuel Dorrego. Vida y muerte de un líder popular", Prohistoria, Año XIX, núm. 26, dic. 2016, pp. 139-144. 
Comienzo agradeciendo a Julio y a Daniel por la lectura cuidadosa y los ricos comentarios. Voy a responder acudiendo a todo el libro y no solo al capítulo debatido en el encuentro.

Empiezo abordando en conjunto el tema que provocó más inquietudes en ambos, la popularidad de Dorrego. ¿Qué quiere decir que era un líder "popular"? Que concitaba la adhesión de personas pertenecientes a las clases populares. Los líderes de este tipo en la época no tenían en general origen plebeyo, sino que eran miembros de la elite que lograban el apoyo de los de abajo a través de diferentes acciones. Dorrego fue el primero, con Miguel Soler, que jugó ese papel en la Buenos Aires posrevolucionaria, pero luego hubo varios otros, cada uno con su estilo y en un lugar que iba cambiando: Juan Manuel de Rosas, Bartolomé Mitre, Adolfo Alsina, Leandro Alem... (Hipólito Yrigoyen y Juan Domingo Perón son así parte de una tradición de larga data). Es inevitable que al pensar en liderazgos populares les pongamos siempre una suerte de "medidor": cuánto pugnaron "realmente" por los intereses de los subalternos y por su igualación. Ahí cada uno de los líderes mencionados tuvo posiciones distintas. Y sin embargo todos fueron "populares", ya que fueron votados, apoyados y celebrados por miembros del "bajo pueblo".

Creo que para apreciar el alcance y las implicancias de la popularidad de Dorrego es necesario no centrarse tanto en él como en sus seguidores. Si llegué a escribir esta biografía fue porque me dediqué durante mucho tiempo a explorar la participación política del bajo pueblo porteño en los años que siguieron a la revolución de $1810 .{ }^{1}$ La conversión de aquel en un factor clave de la vida pública porteña permitió que algunas figuras apelaran a su favor como

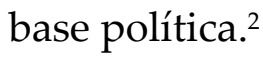

¿Había "oportunismo" en Dorrego al hacerlo? Indudablemente, pero es muy complicado aislar esa variable de la convicción cuando algunas posiciones se vuelven recurrentes y no cambian. ¿Le interesaban "genuinamente" los intereses populares o solo los defendía para escalar políticamente? Es imposible saberlo ya que no dejó testimonios al respecto, pero una cosa y otra no tienen por qué ser antagónicas. Ambiciones personales y causas colectivas pueden aglutinarse perfectamente y en varios momentos de la biografía mostré

\footnotetext{
${ }^{1}$ Fundamentalmente en ;Viva el bajo pueblo! La plebe urbana de Buenos Aires y la política entre la Revolución de Mayo y el rosismo, Buenos Aires, Prometeo libros, 2006.

2 Cuando comencé la biografía quería sobre todo dedicarme a ese aspecto que me interesaba particularmente: las formas de su popularidad, utilizando biografías previas para cubrir otros aspectos. Pero luego cambié de idea y lo que era un trabajo corto se transformó en una investigación de años, para poder abordar distintas facetas del personaje. La impronta popular quedó en el título porque es la que me pareció más relevante, pero podría haber sido "un líder federal" y era igualmente correcto. El nombre que quería ponerle al libro era "Manuel Dorrego. La cabeza de la Hidra", aludiendo a la carta en la que le piden a Lavalle que lo fusile para cortar la cabeza de ese ser mitológico. Por "Hidra" se entiende tanto la presencia popular como la anarquía que los decembristas de 1828 identificaban con el federalismo. El título cerraba mejor, pero me advirtieron con justicia que era más críptico para el público y por eso se cambió.
} 
ejemplos de ello. En todo caso, lo importante para los plebeyos que adherían a Dorrego era que este llevaba algunas de sus demandas a la legislatura o al gobierno. En 1823 Dorrego asumió como diputado y enseguida pidió la supresión de la leva; durante años fue consecuente con ese reclamo tan caro al mundo popular, hasta que una vez gobernador en 1827 puso fin al reclutamiento forzoso.

Quiero destacar la periodización del personaje. La habilidad del joven militar para relacionarse con sus soldados no lo hizo un líder, solo le otorgó herramientas que luego utilizaría. El giro de Dorrego se dio tras la imposibilidad de transformarse en el hombre del orden en Buenos Aires, rechazado por los sectores dominantes de la provincia en 1820. Ahí fue cuando, habiendo visto en ese año terrible el potencial de la actuación popular, Dorrego empezó a trabajar activamente para conseguir la adhesión plebeya y construir con ella una base electoral que le permitiese competir contra los "ministeriales", que empleaban los recursos estatales para ganar todas las elecciones en la primera mitad de la década de 1820. Su carisma, la utilización de redes "clientelares" que dirigían los "tribunos de la plebe" barriales que lo apoyaban, $\mathrm{y}$ ciertos gestos personales como vestirse al modo popular a pesar de tener claramente otro origen social -la distancia estaba clara en el mote "padre de los pobres", marcando que él no era uno de esos pobres- jugaron un papel. Pero el éxito de su estrategia se completó con saber apreciar y explotar demandas populares, en un contexto en el cual estas pesaban. La politización popular ya existía; Dorrego no la promovió sino que intentó dirigirla.

Su discurso atacaba los "aristócratas" porque ese tópico circulaba por todas partes. El grito "viva el bajo pueblo, mueran los de casaca y levita, y viva el gobernador Dorrego" no lo lanzó él, aunque pudiera estar complacido al escucharlo. La idea de que las "chaquetas" se enfrentaban a las "levitas" iba más allá de las posiciones que él explicitó: igualdad de derechos políticos para la mayoría de los hombres, límite a los abusos de las autoridades sobre los de abajo, oposición a quienes querían afianzar las jerarquías sociales. Fueron sus seguidores los que le dieron al movimiento que encabezaba Dorrego un componente clasista que fue más allá de las propuestas -el "programa"- del líder. El federalismo canalizó buena parte de las tensiones sociales y raciales de la Buenos Aires posrevolucionaria, y eso continuaría en los años de Rosas.

¿Por qué Dorrego no quiso movilizar a sus adherentes plebeyos en diciembre de 1828 cuando la conspiración en su contra era evidente, desconcertando a contemporáneos e historiadores? Trato el asunto in extenso en el libro, solo diré aquí que fue menos por un miedo "de clase" al desborde popular que una consecuencia de su carrera política. Siempre intentó ser aceptado como un hombre de orden frente a quienes lo acusaban de díscolo y loco, su apelación a lo popular era electoral y no en otras formas; intentó combatir el levantamiento por vías "legales" y le salió mal. 
Finalmente, una observación sobre la geografía de su popularidad. Fue mi investigación sobre la ciudad la que me condujo a estudiar a Dorrego. Es cierto que era un dirigente que centraba en el ámbito urbano su actuación, pero su ascendente superó los límites de la ciudad. Si los artesanos o los miembros de las sociedades africanas eran parte indudable de la "plebe urbana", mucha población "de poncho" -hombres y mujeres- circulaba entre el campo y la ciudad permanentemente. Además, Dorrego defendió como legislador intereses de los labradores, y con medidas como la prohibición de la leva alcanzó a todos los paisanos. Su popularidad fue entonces también rural y la demostración contundente de ello fue el gran levantamiento de la campaña que siguió a su fusilamiento. Se ha demostrado que Rosas, que terminó siendo el gran beneficiario de ese estallido, no lo preparó. En la organización inicial se destacó el mayor Mesa, un cercano colaborador de Dorrego -fue su único acompañante cuando el gobernador debió huir del Fuerte ante el avance de Lavalle-, que luego fue capturado y fusilado por los decembristas. Pero la indignación era general y se acrecentó con la circulación de las cartas de despedida de Dorrego, de sus litografías y de versos como "fusilan a un bienhechor". ${ }^{3}$ Que Rosas fuera un líder de base rural y que llegara al poder gracias al triunfo de las partidas federales no debe ocultar que fue la muerte de Dorrego la que llevó a algo nada común: un movimiento popular espontáneo en la campaña. El problema es que tendemos a pensar en 1829 como un comienzo y no como un final; pero también lo fue.

La cuestión de la patria a la que alude Pinto es crucial. Fue efectivamente un principio identitario clave de la sociedad colonial y siguió siéndolo en el período revolucionario. El cambio fundamental fue que Patria integraba una tríada, "Dios, Patria, Rey", cuya unidad se rompió con la revolución. En unos pocos años la lucha pasó a ser para los revolucionarios de la Patria contra el Rey (nadie puso a la religión en cuestión). Luego, en la radicalidad de esos años agitados, la patria se asociaría con principios republicanos y el rey no como un personaje puntual sino con la monarquía como sistema. El desplazamiento es muy interesante. En los primeros años revolucionarios ambos bandos se proclamaban los verdaderos patriotas que luchaban contra los que no lo eran. Pero con el tiempo, en distintos lugares de América los revolucionarios se adueñaron del principio de patria, sobre todo porque los realistas enfatizaron su identificación con el rey (un ejemplo, el grito realista en el norte del Perú de 1821 “¡Qué Patria, ni qué mierda! ¡Viva el Rey, y muera el pirata Ladrón de San

\footnotetext{
3 Véanse GONZÁLEZ BERNALDO, Pilar "El levantamiento de 1829: el imaginario social y sus implicaciones políticas en un conflicto rural", en Anuario IEHS, núm. 2, Tandil, 1987, pp. 137176, y FRADKIN, Raúl ¡Fusilaron a Dorrego! O cómo un alzamiento rural cambió el curso de la historia, Buenos Aires, Sudamericana, 2008.
} 
Martín!"). ${ }^{4}$ La preexistencia del concepto de patria le permitió convertirse, con otro contenido político, en un referente exitoso para los revolucionarios. Todos proyectaron en ella distintas expectativas; diversos autores mostraron cómo "patria" se podía asociar con suelo, comunidad, libertad, justicia distributiva... Y el concepto mantuvo su centralidad durante todo el siglo XIX. ${ }^{5}$

Respecto del federalismo, tema al que se refiere Santilli, digo: efectivamente Dorrego encabezó con otros federales porteños una facción que tenía diferencias con los "neofederales" porteños de Rosas, Arana y Anchorena, y también con los federales de las provincias. Aclaro, como hago en el libro, que eso no lo "descolocaba" en el movimiento, ya que era una pata tan importante como las de los que se hicieron federales más tarde que él en Buenos Aires o los del Interior. Dorrego ya mostró preferencias federales en 1816 y abrazó con fuerza esa causa cuando comenzó el debate sobre cómo organizar el país desde 1824. Es cierto que su derrota y su muerte permitieron que desde Sarmiento a Halperín Donghi sostuviesen que no tenía lugar, que sobraba, pero traté de mostrar en el libro que es una explicación ex post y no refleja lo que ocurría. Ambas miradas, y las de muchos otros autores, están condicionadas por el rosismo, como si este hubiese sido un desenlace inevitable, fatal, de la revolución, o un emergente obvio de la estructura social y política de la época. Nadie presentó en su momento al proyecto dorreguista como utópico o como desfasado, es una lectura posterior. Y evitando el historicismo se puede afirmar que la derrota de Dorrego y los suyos fue en buena medida contingente, no estaba inscripta en nada. No era menos federal ni viable su proyecto que el de las otras facciones.

¿En qué consistía ese proyecto? No era confederacionista sino federal, buscando un estado central débil -la impronta jeffersoniana- pero con un papel clave. Por lo tanto, requería también una constitución. Es cierto que a Dorrego se le complicaba conciliar posturas muy diversas dentro del federalismo: su apoyo a la libertad de cultos con la intransigencia contra ella en varias provincias, el deseo de estas de compartir los beneficios aduaneros de Buenos Aires contra la oposición a permitirlo de los neofederales porteños. En su breve gobierno de 1827-1828, Dorrego logró la paz con las provincias pero no llegó a abordar la cuestión aduanera, y aunque en esta última etapa de su vida se mostró como alguien alejado de su porteñismo inicial y proclive a negociar

\footnotetext{
4 DIÉGUEZ DEZA, Víctor “'Viva el rey y muerta el pirata ladrón'. Insurrección realista en la sierra de Trujillo y el cumpleaños de Fernando VII, Cajabamba, 1821", en Síntesis social, año VI, núm. 6-7, Lima, 2015, p. 401.

${ }^{5}$ He trabajado sobre los significados de "patria" en el período en un tomo colectivo sobre el mismo concepto en distintas partes del espacio iberoamericano (DI MEGLIO, Gabriel "Patria", en FERNÁNDEZ SEBASTIÁN, Javier (dir.) Diccionario político y social del mundo iberoamericano. Conceptos políticos fundamentales 1770-1870 [Iberconceptos II], tomo 8, editado por Georges Lomné, Universidad del País Vasco/Centro de Estudios Políticos y Constitucionales, Madrid, 2014).
} 
algunos privilegios para conseguir la unión, es indudable que no le hubiera sido fácil encarar esa disyuntiva de haberlo intentando.

En cuanto a su postura económica, es cierto como marca Santilli que Dorrego estaba alineado discursivamente con el librecambio, pero en la práctica su posición fue más compleja. Si bien mostraba la misma reverencia que todos hacia las ideas de Adam Smith, también afirmaba que ellas debían ser aplicadas más adelante, cuando se hubiera superado el atraso inicial. Para conseguirlo fue un activo promotor del proteccionismo agrario en 1824 -cuando como diputado impulsó exitosamente la prohibición de la importación de harinas- y también durante su gobierno colocó precios máximos a la carne y el pan cuando hubo riesgo de escasez en 1827, para no afectar a los consumidores.

Para terminar, el "enigma" que plantea Pinto no quiso ser tal. Siempre me gustaron los epígrafes que hacen referencia al contenido de un capítulo, pero nunca había utilizado ese recurso en mis trabajos. Sin embargo, mientras hacía el plan de esta obra se me ocurrió que una buena síntesis de los efectos de la muerte de Dorrego -nada menos que una rebelión popular- estaba en la letra de la canción que puso fin a la carrera de The Beatles, "The End", que puede traducirse como "y en el final, el amor que te llevás, equivale al amor que generás". ${ }^{6}$ Primero descarté por poco ortodoxa la posibilidad de emplear un epígrafe que no proviniera de una frase de época, del pensamiento político clásico o de la literatura, como se estila, pero enseguida se me ocurrió que un tema de Duran Duran que escuchaba mucho de chico, "Wild boys", tenía un frase que describía acertadamente la época de joven aventurero de Dorrego en el Ejército Auxiliar del Perú: "los chicos salvajes siempre brillan”. A partir de ahí comencé a buscar epígrafes posibles en canciones rockeras -marca de autor, ya que es el tipo de música que más escucho- y fui encontrando varios que me parecieron adecuados para hablar de lo que trata cada capítulo (como los dos iniciales provenían de música en inglés, acudí solo a ella, pero traduciendo en tono "argentino"). De todos modos, mucho después, cuando terminé el libro, me pareció que había algo más en esa elección, y lo señalé al cerrar el epílogo: si algo caracterizó a Dorrego fue su intensidad en distintos aspectos. Era una figura política de acción. En ese sentido, y usando expresamente un anacronismo, hoy se podría decir que "rockeaba".

Buenos Aires, septiembre de 2016

\footnotetext{
6 "And in the end, the love you take is equal to the love you make" ("make" implica un juego de
} palabras con "el amor que hacés", que acá tomé como crear, generar, a los efectos del epígrafe). 